\title{
A study on contraceptive use among married women of reproductive age group in a rural area of Tamilnadu, India
}

\author{
Rema V. Nair ${ }^{1}$, Vishnu G. Ashok ${ }^{2}$, Prashant V. Solanke ${ }^{2 *}$ \\ ${ }^{1}$ Department of Obstetrics and Gynaecology, ${ }^{2}$ Department of Community Medicine Sree Mookambika Institute of
} Medical Sciences, Kulasekharam, District Kanyakumari, Tamil Nadu, India

Received: 18 July 2016

Accepted: 12 August 2016

\section{*Correspondence:}

Dr. Prashant V. Solanke,

E-mail: drprashantsolanke@ rediffmail.com

Copyright: ( $)$ the author(s), publisher and licensee Medip Academy. This is an open-access article distributed under the terms of the Creative Commons Attribution Non-Commercial License, which permits unrestricted non-commercial use, distribution, and reproduction in any medium, provided the original work is properly cited.

\begin{abstract}
Background: India was the first country in the world to formulate the national family planning programme in the year 1952 with the objective of "reducing the birth rate to the extent necessary to stabilize the population at a level consistent with requirement of national economy. The objective of this study was to study contraceptive use among married women of reproductive age group in a rural area of Tamilnadu.

Methods: A cross sectional study was conducted from December 2014 to January 2015 in Sree Mookambika institute of medical Sciences, Kulasekharam among the married women in eligible couples group attending the hospital. Sample size was calculated to be 84. Inclusion criteria: married couple with female in age group of 15 - 45 years and sexually active and having the ability to communicate in local language.

Results: The mean age was 30.95 years $(\mathrm{SD}=6.421)$. Formal education was received by $100 \%$ women. Majority are Christians (48.8\%) followed by Hindu (46.4\%) and Muslim (4.8\%). Among the respondents $(\mathrm{n}=84), 33.7 \%, 41.7 \%$, $2.4 \%$ and $22.6 \%$ had parity of $1,2,3$ or more and none respectively Most of the women (71.4\%) belonged to middle class group. $94 \%$ of women were aware of sterilization. This study shows a significant association between number of children and contraception usage $(\mathrm{p}<0.05)$. As parity increases contraception usage rate increases. Similar association is seen between number of male children and contraception practice $(0.006)$. Also acceptance for permanent method of family planning increased with increasing parity $(0.00)$ and number of male children $(0.04)$.

Conclusions: The study reveals good knowledge and favorable attitude of rural couples towards contraception. Contraceptive knowledge and practice was influenced by exposure to family planning messages.
\end{abstract}

Keywords: Contraceptive, Reproductive age group, Family planning

\section{INTRODUCTION}

India was the first country in the world to formulate the national family planning programme in the year 1952 with the objective of "reducing the birth rate to the extent necessary to stabilize the population at a level consistent with requirement of national economy. ${ }^{1}$

Family planning assists "families in achieving the number of children desired with appropriate spacing and timing, ensuring optimal growth and development of each family member". Failure to plan a pregnancy can adversely affect the health of the mother, the child and the families as a whole. It also protect from high-risk pregnancy, unsafe abortion, reproductive tract infection and STDs including HIV/AIDS

The international conference on population and development (ICPD) defined voluntary family planning services as a fundamental human right as well as couples' right. Gaps in reproductive health/family planning and sexual health care account for nearly $1 / 5^{\text {th }}$ of the 
worldwide burden of illness and premature death and $1 / 3^{\text {rd }}$ of illness and death among reproductive age group women. $^{2}$

The population of India at 0.00 hours of $1^{\text {st }}$ march 2011 , as per the provisional population totals of census 2011 is $1,210,193,422$ compared to a total of $1,028,737,436$ in 2001. In absolute terms, the population of India has increased by more than 181 million during the decade 2001 - 2011. Three most populous ones, China, India and USA together account for four of every ten persons of the world. At present a little more than one out of every 6 persons in the world is from India.

The United Nations has estimated that the world population grew at an annual rate of 1.23 percent during 2000 - 2010. With a definite slowing down of population growth in china, it is now estimated that by 2030, India will most likely overtake china to become the most populous country on the earth with 17.9 percent population living here. ${ }^{3}$

According to 2011 census, total population in Tamil Nadu is 7, 21, 47, 030 and the annual growth rate is $15.6 \%(2001-2011)^{4}$

The TFR for the country remained constant at 2.6 during 2008 and 2009 with Bihar reporting the highest TFR at 3.9 while Kerala and Tamil Nadu continued its outstanding performance with the lowest TFR of 1.75.

TFR

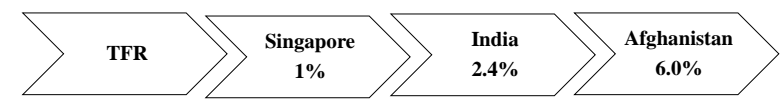

In India

$\left.\left.\left.\sum \begin{array}{c}\text { Andhra Pradesh } \\ \text { Highest }\end{array}\right\rangle \begin{array}{c}\text { Tamil Nadu } \\ \text { Lowest }\end{array}\right\rangle \begin{array}{c}\text { Bihar } \\ \text { 6th position }\end{array}\right\rangle$

In 1965 - 2009 periods, contraceptive usage has more than tripled from $13 \%$ of married women in 1970 to $48 \%$ in 2009 and the fertility rate has more than halved from 5.7 in 1966 to $2.4 \%$ in 2012 but the national fertility rate is still high enough to cause long term population growth. ${ }^{6}$

Family planning in India is based on efforts largely sponsored by Indian govt. Evidence concerning contraceptive use or non-use, choice of method and adherence to regimen may help to guide clinical and public health education programs and policies to provide optimal contraceptive choice and to optimise adherence and thereby reducing unintended pregnancy. Demographic changes often take years to be evident, making it difficult to predict how today's an action will affect the future size and distribution of populations.
Small changes in childbearing trends today have huge implications for future population size.

Keeping in view the above points, the present study was designed to find out the contraceptive practice and identifying the different variables which affect the contraceptive usage among the married women in eligible couples group attending Sree Mookambika institute of medical Sciences, Kulasekharam.

According to NFHS III survey 2005-06, 98 percent of women know one or more methods of contraception. Female sterilization is the most widely known method among women (97\%). Among the three spacing methods offered by the government family planning programme (pill, IUD, and condom), the pill is most widely known among women (85\%).Emergency contraception is known to only 11 percent of women. Contraceptive prevalence rate in India is 56\%. Female sterilization accounts for two-thirds of total contraceptive use and the highest $(37 \%)$. Among the spacing methods, the most widely used methods are condoms and rhythm (5\%). The use of the three modern spacing methods together accounts for 18 percent of the CPR. Unmet need for family planning was $13 \%$ in India and $8.9 \%$ for Tamil Nadu. More married women with unmet need live in India than in any other country - approximately 31 million (urban $-8.8 \%$, rural $-9.1 \%$ ). ${ }^{7}$

\section{According to DLHS III 2005-06. ${ }^{8}$}

Table 1: Current use of family planning methods.

\begin{tabular}{|lllllll|}
\hline Any method (\%) & 54.0 & 51.1 & 60.2 & 52.5 & 48.8 & 61.9 \\
\hline $\begin{array}{l}\text { Any modern } \\
\text { method (\%) }\end{array}$ & 47.1 & 44.4 & 53.0 & 45.2 & 42.0 & 53.4 \\
\hline $\begin{array}{l}\text { Female } \\
\text { sterilization }\end{array}$ & 34.0 & 34.1 & 34.6 & 34.3 & 34.1 & 34.7 \\
\hline $\begin{array}{l}\text { Male } \\
\text { sterilization }\end{array}$ & 1.0 & 1.0 & 0.7 & 0.9 & 0.9 & 0.9 \\
\hline Pill (\%) & 4.2 & 4.1 & 4.4 & 3.5 & 3.0 & 4.7 \\
\hline IUD (\%) & 1.9 & 1.4 & 2.9 & 1.8 & 1.1 & 3.7 \\
\hline Condom (\%) & 5.9 & 3.8 & 10.6 & 4.6 & 2.8 & 9.3 \\
\hline $\begin{array}{l}\text { Any traditional } \\
\text { method (\%) }\end{array}$ & 6.7 & 6.5 & 7.2 & 7.2 & 6.8 & 8.4 \\
\hline
\end{tabular}

In 2005, the contraceptive prevalence rate in Tamilnadu is $55.3 \%$ for the whole sample, which represents the state. It is 55.8 percent for rural and 54.6 percent for urban areas. $^{9}$

Contraceptive knowledge, attitude and practice among eligible couples of rural Haryana. ${ }^{10}$

Results showed that the overall knowledge about any method of contraception was $97.2 \%$. The knowledge was higher for female sterilization (93.2\%) and low for spacing methods $(86.8 \%, 77.6 \%$, and $91.2 \%$ for oral pills, IUCD, and condom respectively) and male sterilization $(86.2 \%)$. $59.2 \%$ of the interviewed couples were 
practicing family planning methods. Female sterilization was the most common chosen method used by $46.0 \%$ of couples. Couples not practicing contraception were $40.8 \%$.

The objective of this study was to study contraceptive use among married women of reproductive age group in a rural area of Tamilnadu.

\section{METHODS}

A cross sectional study was conducted from December 2014 to January 2015 in Sree Mookambika institute of medical Sciences, Kulasekharam among the married women in eligible couples group attending the hospital. The ethical requirements were fulfilled. Sample Size is calculated by $[\mathrm{Z}$ (alpha)] 2PQ/d2. Sample size was calculated to be 84 . Study was interview based. Systemic random sampling was used. All the selected females were interviewed, based upon a semi-structured pre designed and pre-tested performa after taking consent from the subject. Confidentially of the data were ensured to the study participants. The participation was on voluntary basis.

\section{Inclusion criteria}

Married couple with female in age group of 15 - 45 years and sexually active and having the ability to communicate in local language.

\section{Exclusion criterion}

- Unmarried women

- Participants not willing to respond even after requesting and ensuring confidentiality were excluded from the study

- Females suspected to be suffering from infertility were also excluded from the study. Inability to conceive after 1 year of marriage and cohabitation with husband was taken as the criterion for infertility.

Interview with each woman lasted for 15-20 minutes. The questionnaire consisted of demographic characteristics including age, marital status, level of education, and employment. Questions were asked regarding previous pregnancies and family planning method used knowledge about contraceptive methods like condoms, combined oral contraceptive pills (COC), injectable hormones, intrauterine contraceptive device (IUCD), and natural methods. The knowledge of permanent method of contraception like tubal ligation and vasectomy was also assessed. The source of knowledge and the women's attitude towards the contraception in the form of motivation, involvement of spouse and/or self and acceptability of contraception were recorded. Questions regarding factors responsible for non-use of contraception were also asked. Descriptive analysis was done and the results were given in percentages. SPSS 20.0 was used to analyze the data.

\section{RESULTS}

A total of 84 married women in age 15 - 45 years were studied. The mean age was 30.95 years $(\mathrm{SD}=6.421)$.

Table 2: Education.

\begin{tabular}{|lll|}
\hline & Frequency & Percent \\
\hline Profession/honours & 24 & 28.6 \\
\hline Graduate/pg & 24 & 28.6 \\
\hline $\begin{array}{l}\text { Intermediate/post high school } \\
\text { diploma }\end{array}$ & 12 & 14.3 \\
\hline High school certificate & 11 & 13.1 \\
\hline Middle school certificate & 9 & 10.7 \\
\hline Primary school certificate & 4 & 4.8 \\
\hline 84 & & 100.0 \\
\hline
\end{tabular}

Table 3: Knowledge and awareness of contraception and source of information among women interviewed.

\begin{tabular}{|c|c|c|}
\hline \multicolumn{3}{|c|}{ A wareness and source of knowledge of contraception } \\
\hline \multicolumn{3}{|c|}{ Awareness of contraception } \\
\hline Yes & 84 & $100 \%$ \\
\hline \multicolumn{3}{|l|}{ Family planning means } \\
\hline Pregnancy prevention & 37 & $44 \%$ \\
\hline Birth spacing & 36 & $42.9 \%$ \\
\hline Planning for better future & 49 & $58.3 \%$ \\
\hline Birth limiting & 45 & $53.6 \%$ \\
\hline Others specify & 1 & $1.2 \%$ \\
\hline \multicolumn{3}{|l|}{ Methods known } \\
\hline Natural methods & 58 & $69 \%$ \\
\hline Oral pills & 51 & $60.7 \%$ \\
\hline Injectable & 23 & $27.4 \%$ \\
\hline Implants & 18 & $21.4 \%$ \\
\hline IUCD & 56 & $66.7 \%$ \\
\hline Barrier methods & 59 & $70.2 \%$ \\
\hline Spermicides/jelly/foams & 18 & $21.4 \%$ \\
\hline Emergency contraception & 28 & $33.3 \%$ \\
\hline Sterilization & 79 & $94 \%$ \\
\hline \multicolumn{3}{|l|}{ Source of information } \\
\hline Husband & 13 & $15.5 \%$ \\
\hline Health personnel & 34 & $40.5 \%$ \\
\hline Mass media & 14 & $16.7 \%$ \\
\hline Friends & 6 & $7.1 \%$ \\
\hline Relatives/ neighbours & 4 & $4.8 \%$ \\
\hline Others & 19 & $22.6 \%$ \\
\hline
\end{tabular}

Total is not $100 \%$ as women knew of multiple methods of contraception and several sources of information

Formal education was received by $100 \%$ women. Majority are Christians $(48.8 \%)$ followed by Hindu (46.4\%) and Muslim (4.8\%). 
Among the respondents $(\mathrm{n}=84), 33.7 \%, 41.7 \%, 2.4 \%$ and $22.6 \%$ had parity of 1,2 , 3or more and none respectively Most of the women (71.4\%) belonged to middle class group.

In this study, $100 \%$ had awareness regarding any method of contraception.

$94 \%$ of women were aware of sterilization. The main source of information is health personnel (40.5\%).

Out of 51 women who were aware of oral pills, only $28.6 \%(n=24)$ knew to start the first dose of OCP on the $5^{\text {th }}$ day of menstruation and $20.2 \%(\mathrm{n}=17)$ knew to take the missed pill the moment she remembers.

Among women who were aware of sterilization $(n=79)$, $88.1 \%(\mathrm{n}=74)$ knew that it is a permanent procedure. Out of 56 women who knew about IUCDS, $16.7 \%$, $21.5 \%$ and $61.9 \%$ did not know how it is used, the time of insertion and its contra indications. Among women aware of condoms, majority (45-65\%) knew that it is protective against pregnancy and HIV/AIDS. $28.6 \%$ of women knew about the unsafe period in menstrual cycle that may result in pregnancy.

Out of 84 eligible couples, $75 \%, 48.8 \%, 27.4 \%, 41.7 \%$, $42.9 \%$ and $9.5 \%$ were aware of the contraception availability at government hospitals, private hospitals, dispensaries, primary health centres, pharmacies and others respectively. Even though $100 \%$ of women were aware of family planning measures, only $57.1 \%(n-=48)$ had used contraceptive methods. Sterilization (26.2\%) was the most common method adopted.

Out of 48 , only 40 are still using it. $42.9 \%(n=36)$ did not practice any method of contraception. There were multiple responses to the reason for non-use. Majority didn't feel a need (28.6\%), followed by superstitious beliefs $(6 \%)$, scared of adverse medical effects (4.8\%) and prevents future pregnancies $(3.6 \%)$.

Table 4: The practice of contraception.

\begin{tabular}{|lll|}
\hline \multicolumn{3}{|c|}{ Practice of contraception } \\
\hline Not practised any methods & 36 & $42.9 \%$ \\
\hline Natural methods & 15 & $17.9 \%$ \\
\hline Barrier methods & 12 & $14.3 \%$ \\
\hline Oral pills & 2 & $2.4 \%$ \\
\hline IUCDs & 4 & $4.8 \%$ \\
\hline Sterilization & 22 & $26.2 \%$ \\
\hline Emergency contraception & 6 & $7.1 \%$ \\
\hline
\end{tabular}

*Total is not $100 \%$ as there were multiple responses

Among 8 couples who discontinued, majority (62.5\%) stopped currently because of adverse medical effects.

Table 5: Family planning.

\begin{tabular}{|c|c|c|c|c|c|}
\hline & Strongly agree \% & Agree \% & Disagree $\%$ & Strongly disagree $\%$ & 6 Don't know \% \\
\hline Improves family standard of living & 59.5 & 36.9 & 1.2 & 1.2 & 1.2 \\
\hline $\begin{array}{l}\text { Natural methods of contraception } \\
\text { can prevent pregnancy }\end{array}$ & 29.8 & 35.7 & 13.1 & 4.6 & 16.7 \\
\hline $\begin{array}{l}\text { Family planning should be made } \\
\text { compulsory in India }\end{array}$ & 59.5 & 26.2 & 9.5 & 3.6 & 1.2 \\
\hline $\begin{array}{l}\text { Necessity of educating school } \\
\text { students about family planning }\end{array}$ & 35.7 & 33.3 & 14.3 & 9.5 & 7.1 \\
\hline \multicolumn{6}{|c|}{ Women can become pregnant after she } \\
\hline Stop using OCP & 23.6 & 36.9 & 7.1 & 4.8 & 27.4 \\
\hline Has removed IUCD & 17.9 & 36.9 & 9.5 & 4.8 & 31 \\
\hline
\end{tabular}

$33.3 \%$ were practising the above methods for more than 2 years and majority $(95.2 \%)$ did not experience any side effects. All 6 couples (7.1\%) who had used emergency pills just used it once. $1.2 \%$ of women had become pregnant as a result of contraception failure. Majority of people (65-95\%) showed a positive attitude towards family planning.

This study shows a significant association between number of children and contraception usage $(\mathrm{p}<0.05)$. As parity increases contraception usage rate increases. Similar association is seen between number of male children and contraception practice (0.006). Also acceptance for permanent method of family planning increased with increasing parity (0.00) and number of male children (0.04).

\section{DISCUSSION}

In our study mean age was 30.95 ( $\mathrm{sd}=6.421)$. All women $(100 \%)$ had knowledge of some method of contraception. The findings are similar to prevalence of knowledge reported by Takkar et al $(100 \%)$ but higher than NFHS III (2005-06) which is $98 \%$. $^{7,11}$ 
Knowledge about female sterilization was higher (94\%) and it is low for spacing methods which was similar to the contraceptive prevalence study at rural Haryana and DLHS 3 (2007-08) and also corroborates with the NFHS III data. $7,8,10$

Among spacing methods awareness was higher for condoms $(70.2 \%)$ which corroborates with the study at Liaquat national medical college and hospital, Karachi and DLHS 3 (2007-08) followed by, natural methods (69\%) IUCD $(66.7 \%)$ and OCPs $(60.7 \%)$ respectively. ${ }^{4,12}$

Even though vast majority of women are aware only $57.1 \%$ practiced any method of contraception similar to the contraceptive prevalence rate in Tamil Nadu 2005 $(55.6 \%)$ and NFHS III $(56 \%))^{7,9}$ This suggest gap between awareness and practice. Similar findings are seen in the study at Karachi hospital. ${ }^{12}$

In the present study the awareness regarding sterilization was highest but only $22.6 \%$ practiced the method. Similarly among spacing methods $70.2 \%$ were aware of barrier methods but only $14.3 \%$ had ever used it, $69 \%$ had awareness about natural methods but only $17.9 \%$ had ever used it, $66.7 \%$ had knowledge of IUCDs but strikingly only $4.8 \%$ had ever used, $60.7 \%$ were aware of OCPs but only $2.4 \%$ had ever used it.

Several factors remained responsible for this gap between awareness and practices that include low compliance, lack of knowledge, religious beliefs and fear of side effects of contraception to low decision making power of women.

In our study one of the major reasons for the non-use $(42.9 \%)$ of contraception was that the couples did not feel the need to use any $(28.6 \%)$ whereas the reason was scared of adverse medical effects in a study conducted at a hospital Karachi. ${ }^{12}$

On the other hand among the women, who were using family planning methods, majority $(62.5 \%)$ stopped currently because of adverse medical effects and the findings are similar to the contraceptive prevalence and awareness study done among Qatari women. ${ }^{2}$ It has been shown that the rate of discontinuation is higher among women who have not been adequately counselled about side effects.

It is important as well to see who provides information regarding contraception. The lack of knowledge about contraception has the potential to dramatically affect the providers' ability to extent quality contraceptive care to their patient. In the present study, health personnel and mass media play the major role in awareness, $40.5 \%$ and $16.7 \%$ respectively responded as getting information through them. In contrast several other studies reported as mass media being the major source of information viz contraceptive awareness study among eligible couples of rural Haryana. ${ }^{10}$
It is important for contraceptive providers to have sound knowledge of various methods of contraception and their proper usage to allay fears about contraception. The government is stressing on proper family planning provision but access to quality healthcare and family planning provision should be met with, to make the family planning programme more successful.

In this study even though $33.3 \%$ of couples were aware of emergency contraception only $7.1 \%(n=6)$ ever used it. In contrast awareness regarding emergency contraception is $11 \%$ among women according to NFHS III survey (2005-06) which is lower when compared to this study. ${ }^{7}$

Majority of women (65-95\%) showed positive attitude towards contraception. Similar findings are noted in other studies; $77.5 \%$ in a study conducted at Karachi hospital; but factors like fear of side effects, economic constraints, cultural and religious beliefs, low motivation and nonaccess to providers hinders the use of contraception. ${ }^{12}$

\section{Recommendation}

The couples should be given information about contraceptives by the health personnel to motivate them.

Limitation of this study was hospital based study. So we can-not apply results to general population. As each unit in the study have not get equal chance of selection to be include in this study.

\section{CONCLUSION}

The study reveals good knowledge and favourable attitude of rural couples towards contraception. Contraceptive knowledge and practice was influenced by exposure to family planning messages. Women education and counseling of couples can play an important role to adopt family planning methods. Electronic media, health personnel and government's organizations can play a positive role to provide knowledge and overcome the knowledge/practice gap.

Funding: No funding sources

Conflict of interest: None declared

Ethical approval: The study was approved by the Institutional Ethics Committee

\section{REFERENCES}

1. Kansal A, Chandra R, Kandapal SD, Negi KS. Epidemiological correlates of contraceptive prevalence in rural population of Dehradun District. Indian Journal of Community Medicine. 2005;30(2):60.

2. Arbab AA, Bener A, Abdulmalik M. Prevalence, awareness and determinants of contraceptive use in Qatari women. EMHJ. 2011;17(1):11-8. 
3. Size, growth, rate and distribution of population, 2011. Available at http://censusindia.gov.in/2011prov-

results/data_files/india/Final_PPT_2011_chapter3.pd f. Accessed on 24 January 2015.

4. Tamilnadu census 2013 final report - full details important for TRB, TNTET, TNPSC, TNUSRB Exams. Available at http://www.tnpscportal.in/2013/05/tamilnaducensus-2011-important-data-exams-statisticspopulation-literacy-sex-ratio.html. Accessed on 24 January 2015.

5. Family welfare statistics in India. Available at http://mohfw.nic.in/WriteReadData/1892s/35034920 88FW Statistics 2011 Revised 31 10 11.pdf. Accessed on 24 January 2015.

6. Bora N, Kumar S. Acceptability and usage of contraceptive among women of reproductive age group in hilly areas of Garhwal, Uttrakhand, India. IOSR Journal of Dental and Medical Sciences (IOSR-JDMS)e-ISSN. 2014;13(7):47-51.

7. The National Family Health Survey. Available at http://hetv.org/india/nfhs/nfhs3/NFHS-3-Chapter-05Family-Planning. Accessed on 24 January 2015.
8. Ministry of health and family welfare; DLHS 200708 . Available at http://rchiips.org/pdf/india_report_dlhs-3.pdf.

9. Survey report on contraceptive prevalence in Tamilnadu, 2005. Available at http://www.tnhealth.org/dfw/notification/August201 4/CPR.STUDY 2005.pdf. Accessed on 24 January 2015.

10. Saluja N, Sharma S, Choudhary S, Gaur D, Pandey S. Contraceptive knowledge, attitude and practice among eligible couples of rural Haryana. The Internet Journal of Health. 2009;12(1).

11. Takkar N, Goel P, Dua D. Contraceptive practices and awareness of emergency contraception in educated working women. Indian $\mathrm{J}$ Med Sci. 2005;59:143-9.

12. Khan A, Hashmi HA, Naqvi Z. Awareness and practice of contraception among child bearing age women, conducted at Liaquat national medical college and hospital Karachi. Journal of surgery Pakistan (International). 2011;16(4):179-82.

Cite this article as: Nair RV, Ashok VG, Solanke PV. A study on contraceptive use among married women of reproductive age group in a rural area of Tamilnadu, India. Int J Reprod Contracept Obstet Gynecol 2016;5:3147-52. 